Document downloaded from:

http://hdl.handle.net/10251/107459

This paper must be cited as:

García-Nieves, J.; Ponz-Tienda, JL.; Salcedo-Bernal, A.; Pellicer, E. (2018). The Multimode Resource Constrained Project Scheduling Problem for Repetitive Activities in Construction Projects. Computer-Aided Civil and Infrastructure Engineering. 33(8):655-671. doi:10.1111/mice.12356

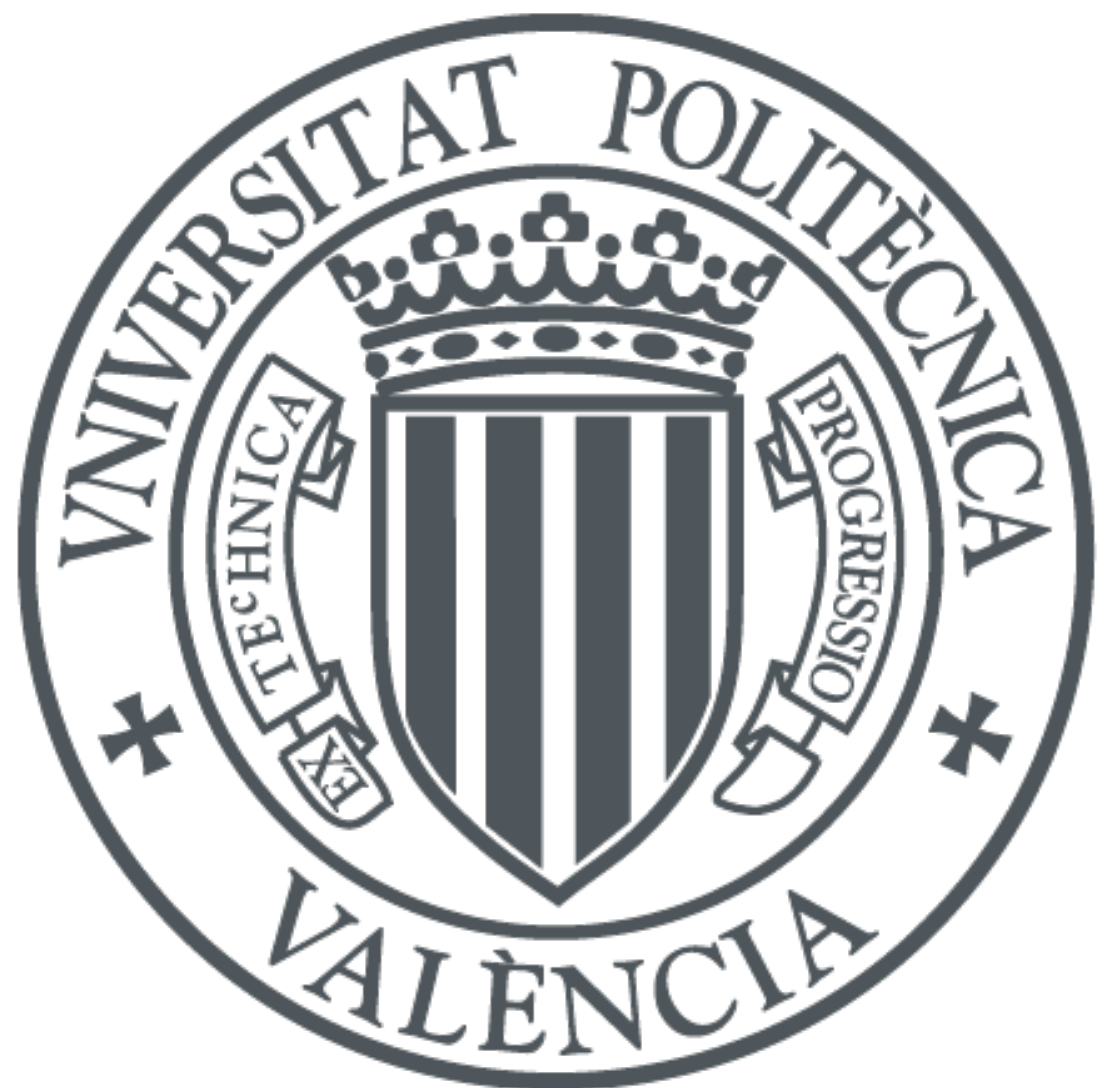

The final publication is available at https://doi.org/10.1111/mice.12356

Copyright Blackwell Publishing Additional Information 


\title{
The Multimode Resource Constrained Project Scheduling Problem for Repetitive Activities in Construction Projects
}

\author{
J. D. García-Nieves, J. L. Ponz-Tienda, A. Salcedo-Bernal \\ Department of Civil and Environmental Engineering. Universidad de Los Andes, Bogotá, Colombia
}

$\&$

E. Pellicer

School of Civil Engineering, Universitat Politècnica de València, Valencia, Spain

\begin{abstract}
In construction projects, resources availability might limit the implementation of ideal schedules. Especially, when repetitive activities are involved, traditional Resource Constrained Project Scheduling Problem (RCPSP) models fail to allocate the resource consumption in an efficient manner. Besides, actual models only provide local optimal solutions and do not incorporate activity acceleration routines. To fulfill this gap, partially, a mathematical optimization model, the multimode RCPSP for repetitive activities in construction projects, is proposed and solved to optimality; it takes into account acceleration routines under real construction scenarios using spreadsheets. The paper shows a complete computational experimentation over a real construction project, considering several scenarios of resource availabilities and continuity conditions. The model allows analyzing the resources efficiency indexes comparing them to resource consumptions, continuity of activities and objective functions that reveal that fragmented activities do not provide better resource efficiency outcomes.
\end{abstract}

\section{INTRODUCTION}

Increasing construction project efficiency in terms of time and cost is one of the most important factors that schedulers have in mind each time a new project starts (Chakraborty, Roy, Das, Jain, \& Abraham, 2009). This implies that practitioners and construction schedulers must take into account resource availability and its efficient consumption, besides the precedence relationships and location conditions. The inefficiency represented by resources consumption fluctuations is expensive and interrupts the workflow (El-Rayes \& Jun, 2009; Koulinas \& Anagnostopoulos, 2013). On the other hand, resource availability might limit the implementation of ideal and non-restrictive schedules; in particular of construction processes, physical resources such as labor force and materials are restricted and might limit the scheduling of activities and construction processes (Benjaoran, Tabyang, \& Sooksil, 2015; Hinze, 2002).

In response to these challenges, literature has classified these scheduling problems as Resource Constrained Project Scheduling Problem (RCPSP henceforth) and Resource Leveling Problem (RLP henceforth) (Harris, 1990; Icmeli, 1993; Özdamar \& Ulusoy, 1995; Herroelen, De Reyck, \& Demeulemeester, 1998; Neumann \& Zimmermann, 1999; Kolish \& Padman, 2001; Demeulemeester \& Herroelen, 2002; Hinze, 2002; Kim, Kim, \& Jee, 2005) (Anagnostopoulos \& Koulinas, 2010; Benjaoran, Tabyang, \& Sooksil, 2015; Ponz-Tienda, Salcedo-Bernal, \& Pellicer, 2016; Herroelen \& Leus, 2005; Ponz-Tienda, Pellicer, Benlloch-Marco, \& Andrés-Romano, 2015). Firstly, the RCPSP aims to minimize the project makespan (or the tardiness in terms of the sum of the finishing time of the activities), preserving the precedence constraints between activities and the resource availability. Secondly, RLP focuses in project's activity re-scheduling in order to minimize the resource consumption fluctuation under a non-restrictive resource context without increasing a previously prescribed project deadline. 
RCPSP and RLP belong to the set of NP-hard (nonpolynomic) problems, and consequently are affected by the "combinatorial explosion" phenomenon (Ponz-Tienda, Salcedo-Bernal, \& Pellicer, 2016; Neumann, Schwindt, \& Zimmermann, 2003; Rieck \& Zimmermann, 2015). This implies that the universe of solutions arises exponentially as the considered number of activities is increased. When a large number of activities are involved, the computational capacity needed to solve this kind of problems was simply unavailable with the current technology. Especially for RLP, exact algorithms are only efficient for small projects (Ponz-Tienda, Salcedo-Bernal, \& Pellicer, 2016).

Moreover, the problem of scheduling repetitive activities in construction projects has been deeply studied since 1950 's, when organization methods for assembly lines where introduced (Nezval, 1958). In practice, there are two main models that allow practitioners to understand the nature of repetitive activities: Line of Balance (LoB) and Linear Scheduling Method (LSM). On the one hand, LoB is a mixture between traditional and linear scheduling derived from activity-on-row networks, where practitioners can observe the delivery rate of finishing of repetitive activities (Su \& Lucko, 2015). This method has been deeply studied since 1970’s (Lumsdem, 1968; O’Brien, 1969). On the other hand, LSM is a linear scheduling technique that allows practitioners to study production rates through the use of work quantity vs. time graphs (Su \& Lucko, 2015).

When LoB and LSM diagrams are used by construction schedulers to analyze the results obtained from traditional RCPSP models, where only finish-to-start relationships between activities were considered, a poor perception of the resources allocation over the space-time, even though resource availability are constrained, is perceived.

If resource restrictions per period are considered, RCPSP should not only minimize the project makespan, but also must help to analyze the efficient resource consumption under different scenarios. Nonetheless, the finish-to-start relationships considered by the traditional models do not allow practitioners to optimize projects taking into account repetitive activities relationships, such as activities overlapping, continuity between sub-activities, and the linear dependences of sub-activities with other activities.

In order to construct a feasible RCPSP approach for repetitive activities in construction projects, several heuristic and metaheuristic algorithms have been proposed to find local optimal solutions. However, to the best of the authors' knowledge, mathematical models considering overlapping, multimode activities execution and linear scheduling for repetitive activities still have pending solutions in global optimality. Furthermore, existent models have not fully integrated the line of balance challenges proposed by Arditi (2002), impeding them to achieve effectiveness. These challenges include: interdependencies among activities, dealing with constraints, non-linear or discrete activities, learning curve effect, optimum crew size, acceleration routine and cost optimization.

The acceleration routine challenge proposed by Arditi (2002), a common and real problem that engineers face with, and MRCPSP mathematical models that solve the problem to optimality are still waiting to be solved by the researchers' community in construction scheduling. In order to partially fulfill these gaps, the authors propose a new mathematical model for construction projects that specifically design to schedule repetitive activities. The formulation of the proposed model for the Multimode Resource Constrained Project Scheduling Problem for Repetitive Activities MRCPSP-RA is based on the following principles: (a) MRCPSP solved to optimality, (b) implementation of realistic construction acceleration routines, (c) relationship between activities based on subactivities relationships and continuity restrictions, (d) discretional activity fragmentation, and (e) serve as an easy criterion to implement scheduling problems in interface such as Excel, in order to generate global optimum solutions.

For the nature of this paper, accelerations routines are conceived as controlled variations of the execution modes within an activity. Mainly, they are implemented to speed up the construction process. The authors' intention is to provide a model that allows different execution modes in each sub-activity of particular activity without incurring in any inefficient hiring and firing conditions. Furthermore, global optimization of the MRCPSP-RA is achieved using Gurobi software engine, which uses linear programming algorithms, such as simplex and interior point-methods algorithms, to explore all the feasible solutions of the linear optimization problem. Following this train of thought, the authors propose a mathematical model that consists on linear objective function and restrictions, which are solved through linear programming optimization.

To expose this proposal properly, this research is organized as follow: First, a literature review of the stateof-knowledge of the resource allocation and resource constrained problems for repetitive activities in construction projects is shown. Section 3 details the proposed model for multimode resource constrained problem for repetitive activity scheduling (MRCPSP-RA). In Section 4, a real residential building construction project is used as example of implementation to evaluate the functionality of the model. Four scenarios, with a total of 60 instances, are considered and solved in the computational experimentation for different resource availability and continuity conditions. Finally, conclusions, limitations and further research are drawn. 


\section{LITERATURE REVIEW}

Several studies have been proposed in order to solve the problems surrounding the resource allocation in repetitive construction projects. These models were built in order to find the optimum starting time for all activities and subactivities in order to minimize a specific objective function. It is important to note that authors understand sub-activities as the fundamental unit of a repetitive activity; for example, a 12-story building, that has 12 identical floors, has 12 identical sub-activities that compose the complete painting activity. Selinger (1980) formulated a one-state variable multi-mode model for repetitive construction based on continuous activity execution. The word "multi-mode" means the model conceived various possible mode of executions per activity. Each mode of execution has different crew size and subsequently, different execution durations and cost. Russel \& Caselton (1988) improved the Selinger proposal considering a two state variable model allowing activity fragmentation through the implementation of predetermined interruption vectors. Lately, to face the inefficiency produced by interruptions, Moselhi and ElRayes (2001) proposed a dynamic multi-mode algorithm for scheduling of repetitive activities that considers, as part of the optimization process, the automatization of interruption options during the activity execution.

Adeli \& Karim (1997) proposed a neural dynamics optimization non-lineal model (CONSCOM) to successfully schedule repetitive and non-repetitive activities in construction projects. The resource allocation problem contemplates sub activity fragmentation, continuity condition, multiple crew-strategies and effects of varying jobs conditions. Further, Adeli \& Senouci (2001) proposed a neural dynamic model for resource scheduling considering precedence relationships, multiple crewstrategies, and time cost trade-off. The model is mainly focused on the total project cost minimization that provides nearly optimal solutions applying artificial intelligence techniques. It considers, in a simultaneous way, cost and project levelling besides resource constraints. The novelty of Adeli \& Senouci (2001) proposal consists on the inclusion of the additional features such as total costoptimization, resource-constrained scheduling, and resource leveling, which outperform CPM. Hegazy (2006) and Hegazy \& Kamarah (2008) developed scheduling computerized models to solve the problem of repetitive activities optimum scheduling in infrastructure maintenance/repair programs and high-rise construction. In particular, efficient repetitive scheduling for high-rise construction was achieved through the implementation of a cost-based genetic algorithm, which successfully incorporate logical floor relationships, work continuity and crew synchronization, productivity factors, work interruptions and resource constraints.
Liu \& Wang (2012) improved existent models enabling multiple execution modes for sub-activities and their discretional fragmentation. Zhang \& Zou (2015) restructured the Liu \& Wang resource allocation model in order to consider simultaneously generalized relationships for the sub-activities, activity fragmentation and one execution mode per activity. Due to the great number of decision variables that can be involved in the application of these models in a real construction context, heuristic and metaheuristic algorithms have been simultaneously proposed by Liu \& Wang (2012) and by Zhang \& Zou (2015) to find local optimum solutions instead of global optimal solutions. More recently, Su \& Lucko (2016) proposed the use of singularity functions to enhance linear scheduling resource allocation by suggesting a new approach that can unify the linear shceduling method (LSM) and the line of balance technique (LoB).

RCPSP and RLP have also been studied by several different authors in the context of repetitive construction projects with real variables (Leu \& Hwang, 2001; Hsie, Chang, Yang, \& Huang, 2009; Zhang \& Zou, 2015) and with integer variables by Ponz-Tienda et al (2013; 2017). Metaheuristic models, built in order to face with multiple intensity execution modes for the activities under resource availability restrictions (MRCPSP henceforth), have partially incorporated the previously exposed Arditi challenges (2002). Leu \& Hwang (2001) proposed a metaheuristic algorithm to establish an optimal resourceconstrained sequence based on activity continuity and only one optimum crew size per activity. Hsie et al. (2009) proposed an evolutionary algorithm that contemplates continuity restrictions, coexistence of multiple modes of execution in the same activity and finish-to-start precedence relationships. In the Hsie et al. (2009) proposal, the execution mode shifting is not allowed at the finishing of each LoB segment but at the end of the time periods. Zhang \& Zou (2015) incorporated the conditioned activity fragmentation, generalized precedence relationship constraints and the coexistence of multiple execution modes; these authors (Zhang \& Zou, 2015) returned to the original conception for shifting mode, in such way that they should be allowed only when LoB length segments (viewed as sub-activities) are finished. Biruk \& Jaskowski (2017), proposed a mixed linear mathematical model for the MRSCSP in repetitive construction projects that guarantee work continuity and optimal crew formation. Lastly, Tang , et al. (2017), ultimate proposed a constraint programming model based on logical relationships to taggle the schedule optimization of linear projects. The model shows great adaptability and flexibility to different optimization scenarios, including resource allocation problems, RLP and MRCPSP.

In spite of all the advances to face the challenges proposed by Arditi (2002), none of these models provide an holistic and global optimal solution for the MRCPSP in 
repetitive scheduling construction projects (MRCPSP-RA), considering activity fragmentation, activity acceleration routines, controlled coexistence of multiple execution modes in a same activity and sub-activity interdependence with all nature of relationships for real and complex construction projects.

\section{THE PROPOSED MRCPSP FOR REPETITIVE ACTIVITIES SCHEDULING IN CONSTRUCTION PROJECTS}

The proposed model considers $P$ number of activities in which identical amounts of $N$ repetitive sub-activities are executed in $M_{q}$ different executions modes (different crew size). In this manner, the optimization model is developed to be applicable in repetitive constructive projects such as residential building projects, were activities like structure, facilities, architectural finishes and mechanics fixings must be executed repetitively in each story.

This proposal implies the use of binary variables denoted as $X_{q j t}$, based on Pritsker, Waiters, \& W

olfe (1969) formulation, in such way that $X_{q j t m}=1$ if a sub-activity $j$ executed in mode $m$ of an activity $q$ is finished in the period $t$, and $X_{q j t m}=0$ otherwise. Additionally, dummy binary variables denoted as $\lambda_{q}$ are used to indicate whether the execution of all the subactivities, that derive from an activity $q$, must be executed in a continuous way. Even though the use of integer variables is more natural than with binary ones, the use of binary decision variables is justified by the time-resource tradeoff nature of the RCPSP problems.

The general formulation of the mathematical model considers the following parameters:

$\begin{array}{ll}P & \text { Number of activities of the project } \\ N & \text { Number of sub - activities in each activity } \\ M_{q} & \text { Number of execution modes in each activity q } \\ \lambda_{q} \in\{0,1\} & \begin{array}{l}=1 \text { if an activity } q \text { must be executed in a continuos way } \\ =0 \text { otherwise }\end{array} \\ d_{q m} & \begin{array}{l}\text { Duration of the sub - activities in activity } q \text { executed } \\ \text { in mode } m\end{array} \\ \gamma_{p_{i} q_{j}} & \text { Lag between two subactivities } i \text { and } j \text {, of activities } p \text { and } q \\ K & \text { Number of renovables resources of the project } \\ a_{q k m} & \text { Consumption of resource } k \text { in the activity } q \text { executed } \\ u_{k} & \text { in mode } m \\ U B & \text { Availability of resource } k \text { per period } t\end{array}$

Moreover, the model decision variables are:

$$
X_{q j t m} \quad \begin{cases}=1 & \text { if a sub - activity } j \text { of an activity } q \text { finishes } \\ & \text { in period } t \text { in mode } m \\ =0 & \text { otherwise }\end{cases}
$$

Two different objective functions are taken into account in this model in order to optimize the construction schedule: the project makespan, computed as the finishing period of the latest sub-activity in the latest activity; and the project tardiness, as the sum of the starting times of all the subactivities of the project (Eq. 1). Both objective functions represent the project duration. On one hand, the project makespan directly expresses the project duration. On the other hand, the project tardiness indirectly express the project duration in such way that, a larger tardiness, indicates that some sub-activities starting times have been postponed. This implicitly suggest that project duration or makespan should stay the same or increase (this relationship between the makespan and the tardiness depend on the activities and sub activities relationships).

$$
\min \left\{\begin{array}{l}
\text { makespan } \sum_{m=1}^{M_{P}} \sum_{t=1}^{U B} X_{P N t m} \cdot t \\
\text { Tardiness } \sum_{m=1}^{M_{q}} \sum_{q=1}^{P} \sum_{j=1}^{N}\left(\sum_{t=1}^{U B} X_{q j t m} \cdot t-d_{q m} \cdot \sum_{t=1}^{U B} X_{q j t m}\right)
\end{array}\right.
$$

Moreover, six restrictions must be added to the model in order to consider real construction conditions. Firstly, subactivities precedence relationships in the same activity must be kept. In this manner, equation 2 limits that a sub-activity $j+1$ in an activity $q$ cannot start until the sub-activity $j$ in the same activity is completely finished (Figure 1).

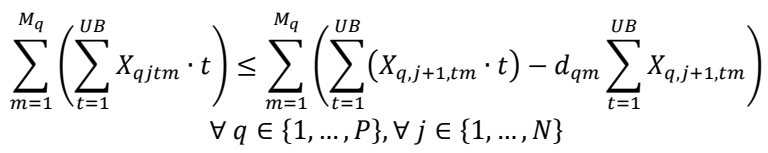

Thirdly, the activity precedence between sub-activities of two interdependent activities is stated in equation 3 , in such way that a sub-activity $j$ in an activity $q$, cannot start, until a sub-activity $i$ located in a predecessor activity $p$ is completely finished. Additionally, a lag time between these two related sub-activities, described as $\gamma_{p_{i} q_{j}}$, is included (Figure 1).

$$
\sum_{m=1}^{M_{p}}\left(\sum_{t=1}^{U B} X_{p i t m} \cdot t\right)+\gamma_{p_{i} q_{j}} \leq \sum_{\substack{m=1 \\ \forall i \text { predecesor of } j}}^{M_{q}}\left(\sum_{t=1}^{U B}\left(X_{q j t m} \cdot t\right)-d_{q m} \cdot \sum_{t=1}^{U B} X_{q j t m}\right)
$$

Equation 3 can be adjusted to deal with all nature of relationships as start-to-start, start-to-finish and finish-tofinish. These modifications are exposed in equations $3 \mathrm{a}, 3 \mathrm{~b}$ and $3 c$ respectively (Figure 1).

$$
\begin{gathered}
\sum_{m=1}^{M_{p}}\left(\sum_{t=1}^{U B}\left(X_{\text {pitm }} \cdot t\right)-d_{p m} \cdot \sum_{t=1}^{U B} X_{\text {pitm }}\right)+\gamma_{p_{i} q_{j}} \leq \\
\sum_{m=1}^{M_{q}}\left(\sum_{t=1}^{U B}\left(X_{q j t m} \cdot t\right)-d_{q m} \cdot \sum_{t=1}^{U B} X_{q j t m}\right) \\
\forall \text { i predecesor of } j
\end{gathered}
$$




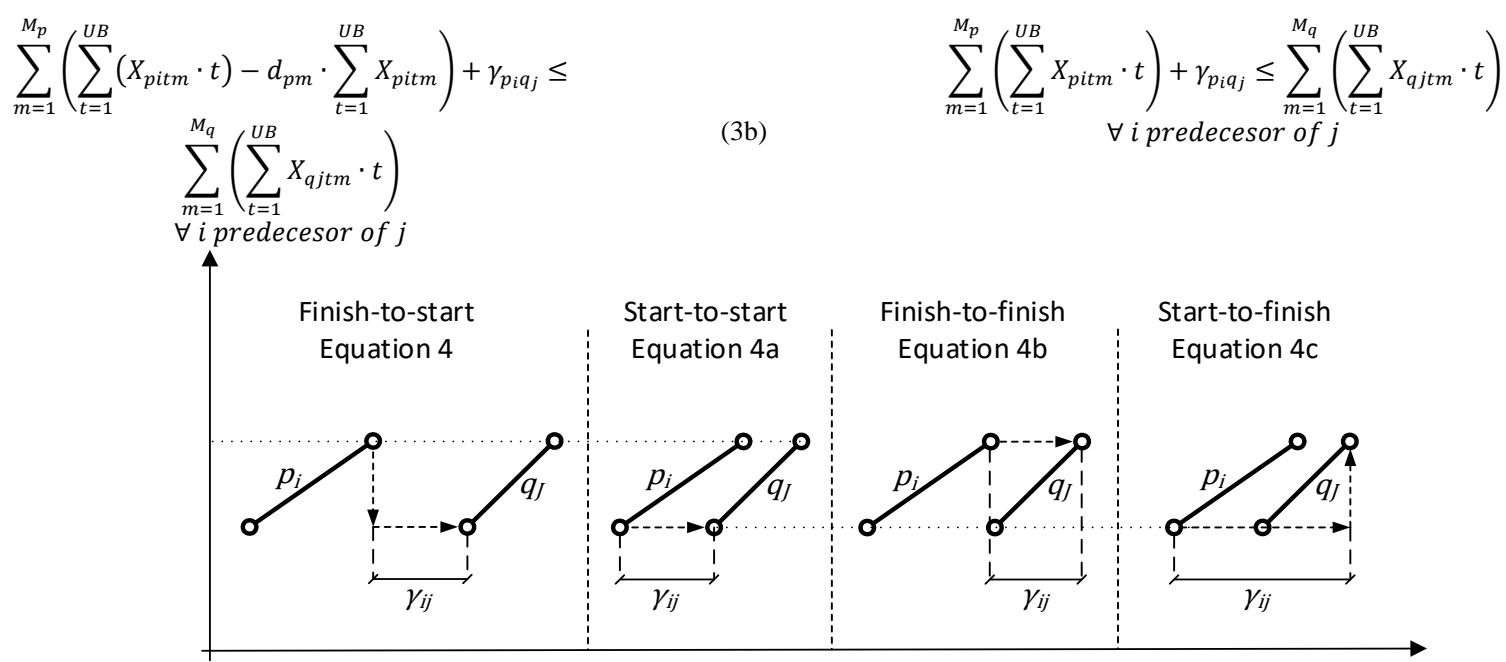

Figure 1 Graphical representation of equations 4 to $4 \mathrm{c}$

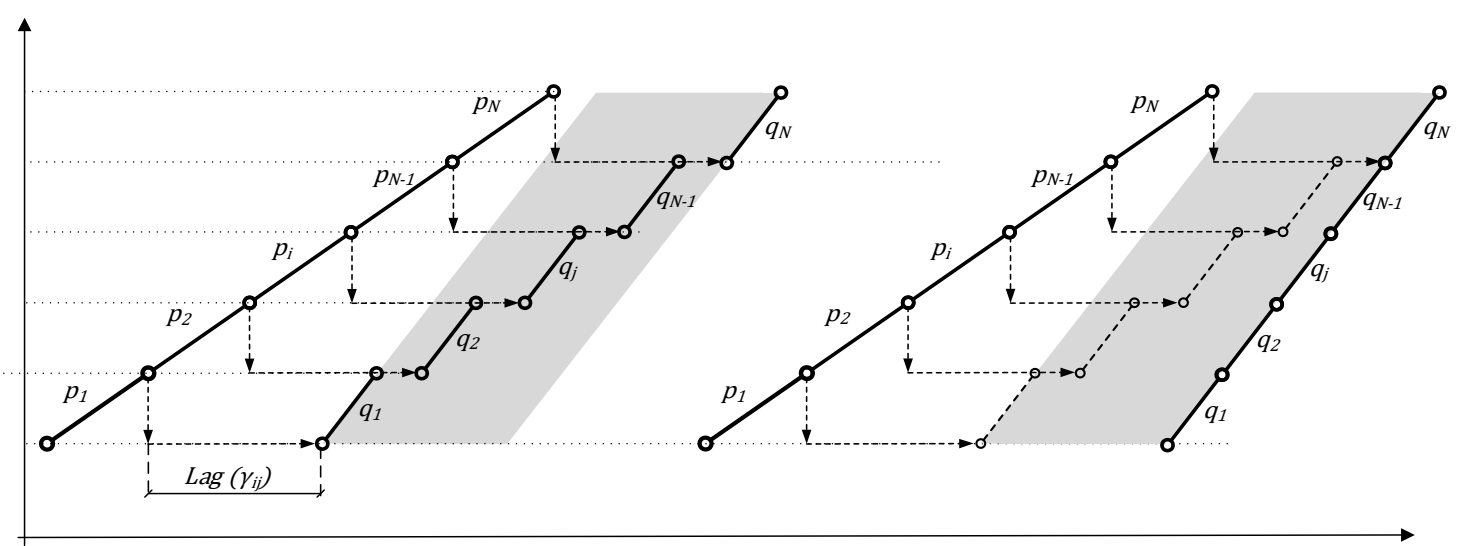

Figure 2 LSM relationships with Lag and continuity implications.

To ensure that activities can be executed discretionally in a fragmented way or must be executed in a continuous way, one dummy variable per activity $\left(\lambda_{q}\right)$ is used. If an activity $q$ must be executed in a continuous way, $\lambda_{q}=1$, and otherwise, $\lambda_{q}=0$. In equation 4 , a discretional constant value of $\delta$ is included to guarantee that the restriction is always true (i.e. $\delta=-1 e 6$ ). Figure 2 illustrates the activity relationships constraints without continuity restriction (left hand side) and under the continuity restriction in the activity execution (right hand side). This restriction force the sub activities to be executed one after the other (continuous activity execution) or not (fragmented activity execution).

$$
\begin{gathered}
\sum_{m=1}^{M_{q}}\left(\sum_{t=1}^{U B} X_{q 1 t m} \cdot t-d_{q m} \cdot \sum_{t=1}^{U B} X_{q i t m}\right)+\delta \cdot \lambda_{q} \geq \\
\sum_{m=1}^{M_{q}}\left(\sum_{t=1}^{U B} X_{q \mathrm{~N} t m} \cdot t\right)-\sum_{\substack{m=1 \\
M_{q}}}^{N} \sum_{j=1}^{N}\left(\sum_{t=1}^{U B}\left(X_{q j t m}\right) \cdot d_{q m}\right)+\delta \\
q \in \in, \ldots, P\}
\end{gathered}
$$

Equation 5 guarantees that each sub-activity is only executed in one construction mode.

$$
\sum_{m=1}^{M_{q}} \sum_{t=1}^{U B} X_{q j t m}=1 \quad \forall \mathrm{q} \in\{1, \ldots, P\}, \forall j \in\{1, \ldots, N\}
$$

Then, as denoted by equation 6, the resource consumption of the whole project in one period cannot exceed the resource availability per period $\left(u_{k}\right)$.

$$
\sum_{q=1}^{P} \sum_{m=1}^{M_{q}}\left(a_{q k m} \cdot \sum_{x=t}^{x+d_{q m}-1} \sum_{j=1}^{N} X_{q j x m}\right) \leq u_{k} \forall t \in\{1, \ldots, U B\}
$$

Finally, in order to enhance the realistic and practical approach of the model, equation 7 ensures that controlled acceleration routines are implemented. Controlled acceleration routine is understood as execution mode changes between sub-activities that correspond to forward shifts crew size changes. This concept emerges to eliminate random mode of execution implementation in each sub 
activity of an activity, which can result in inefficient hiring and firing conditions. It is important to note that the accelerations conceived by the proposed model are only due to crew size increase. The inclusion of acceleration due to learning is still a challenge that should be considered in further research.

$$
\begin{gathered}
j * \sum_{z=m}^{M_{q}} \sum_{t=1}^{U B} X_{q j t z}-\sum_{x=1}^{j} \sum_{t=1}^{U B} X_{q x t m} \geq 0 \\
\forall q \in\{1, \ldots, P\}, \forall j \in\{1, \ldots, N\}, \forall m \in\{2, \ldots, M\}
\end{gathered}
$$

The complete formulation for the mathematical model is stated as follows:

$$
\begin{aligned}
& \min f(x)= \begin{cases}\text { makespan } & \sum_{m=1}^{M_{P}} \sum_{t=1}^{U B} X_{P N t m} \cdot t \\
\text { Tardiness } & \sum_{m=1}^{M_{q}} \sum_{q=1}^{P} \sum_{j=1}^{N}\left(\sum_{t=1}^{U B} X_{q j t m} \cdot t-d_{q m} \cdot \sum_{t=1}^{U B} X_{q j t m}\right)\end{cases} \\
& \text { Subject to: } \\
& \sum_{\substack{m=1 \\
M_{p}}}^{M_{q}}\left(\sum_{t=1}^{U B} X_{q j t m} \cdot t\right) \leq \sum_{m=1}^{M_{q}}\left(\sum_{t=1}^{U B}\left(X_{q, j+1, t m} \cdot t\right)-d_{q m} \cdot \sum_{t=1}^{U B} X_{q, j+1, t m}\right) \forall q \in\{1, \ldots, P\}, \forall j \in\{1, \ldots, N\} \\
& \sum_{m=1}^{M_{p}}\left(\sum_{t=1}^{U B} X_{p i t m} \cdot t\right)+\gamma_{p_{i} q_{j}} \leq \sum_{m=1}^{M_{q}}\left(\sum_{t=1}^{U B}\left(X_{q j t m} \cdot t\right)-d_{p m} \cdot \sum_{t=1}^{U B} X_{q j t m}\right) \quad \forall i \text { predecesor of } j \\
& \sum_{m=1}^{M_{q}}\left(\sum_{t=1}^{U B} X_{q 1 t m} \cdot t-d_{q m} \cdot \sum_{t=1}^{U B} X_{q i t m}\right)+\delta \cdot \lambda_{q} \geq \sum_{m=1}^{M_{q}}\left(\sum_{t=1}^{U B} X_{q \mathrm{~N} t m} \cdot t\right)-\sum_{m=1}^{M_{q}} \sum_{j=1}^{N}\left(\sum_{t=1}^{U B}\left(X_{q j t m}\right) \cdot d_{q m}\right)+\delta \quad \forall q \in\{1, \ldots \mathrm{P}\} \\
& \sum_{m=1}^{M} \sum_{t=1}^{U B} X_{q j t m}=1 \quad \forall \mathrm{q} \in\{1, \ldots, P\}, \forall j \in\{1, \ldots, N\} \\
& \sum_{q=1}^{P} \sum_{m=1}^{P}\left(a_{q k m} \cdot \sum_{x=t}^{x+d_{q m}-1} \sum_{j=1}^{N} X_{q j x m}\right) \leq u_{k} \forall t \in\{1, \ldots, U B\} \\
& j * \sum_{z=m}^{M_{q}} \sum_{t=1}^{U B} X_{q j t z}-\sum_{x=1}^{j} \sum_{t=1}^{U B} X_{q x t m} \geq 0 \forall q \in\{1, \ldots, P\}, \forall j \in\{1, \ldots, N\}, \forall m \in\{2, \ldots, M\}
\end{aligned}
$$

Note that objective function $\min \boldsymbol{f}(\boldsymbol{x})$ is adjusted for finish-to-start relationships, being necessary to include a dummy finishing activity $\mathbf{P}$ to include start-to-finish and start-to-start relationships. This activity has a duration of zero and it has as predecessor activities all the activities of the project. In the following case of study, the real state delivery serves as a dummy variable even though its duration is not cero.

\section{EXAMPLE OF IMPLEMENTATION}

A real construction project was analyzed as an example of implementation in order to illustrate the versatility and applicability of the proposed MRCPSP algorithm. The project consists of four identical residential buildings. Each building has 12 stories; it is scheduled considering seven activities composed of 12 identical sub-activities for a total of 84 work units. The activities considered are Structure, Facilities, Masonries, Carpentry \& Painting, Equipment, Finishing, and Commissioning. For simplicity, the paper only focuses on one of the building's construction schedule. The building project is shown in Figure 3.

The model requires 42000 binary decision variables, considering an upper bound of 250 labor days. It has been implemented in Excel 2016, using Open Solver Optimizer
V.2.8.6 and Gurobi Optimization Software V.7.0.2 (Academic License), requiring a computing time between 2 to 5,443 seconds. The computer used to solve the optimization model was a HP Z640 desktop, with an Intel Xeon E5-2637v4 3.52400 processor and a 32GB DDR42400 (4x8GB) 2CPU RegRAM.

All the relationships between sub-activities of the same activities or dependent activities are finish-to-start relationships. Two construction modes (velocities) are proposed for sub-activities belonging to each activity and only one construction acceleration routine per activity is accepted. Each mode will include the renewable resource consumption per period, expressed in normalized monetary units, and its duration. Also, activities can be restricted to be executed continuously or fragmentally (as considered by the different scenarios analyzed). Furthermore, the project scheduling calendar and LSM is developed in term of labor days based on the Colombian labor calendar.

The precedence relationships and lag between activities, periodical resource consumption and duration per mode of execution, and the continuity conditions are defined by the practitioner depending on the desired scenarios. Table 1 displays the precedence relationships and resource consumption conditions of the project. As an example, continuous execution in all activities of the project is also proposed. As mentioned in the model description, each 
activity has a name, an assigned number $q_{j}$, and a predecessor $p_{i}$. Column $p_{i} q_{j}$ stands for the number of the sub-activity $i$, in the predecessor activity $p$, that must be executed before sub-activity $j$ in activity $q$ starts.

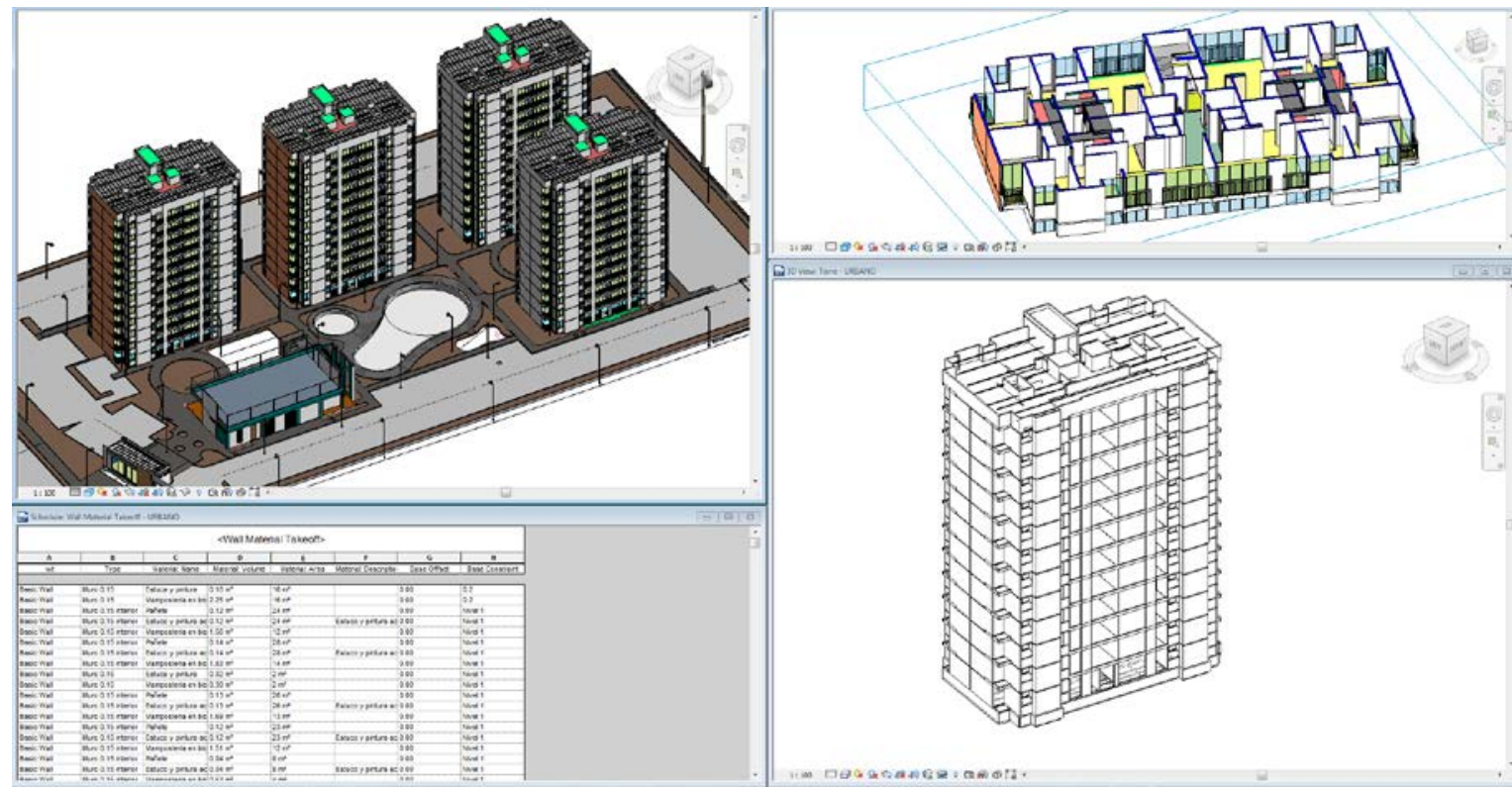

Figure 3 BIM model of the Example of Implementation.

Table 1

Conceptual data model representation for the example of implementation

\begin{tabular}{cccccc}
\hline Activity & $q_{j}$ & $p_{i}$ & $p_{i} q_{j}$ & $\gamma_{p i q j}$ & $\lambda_{p q}$ \\
\hline Structure & 1 & & & 0 & 1 \\
F.Instalations & 2 & 1 & 5 & 0 & 1 \\
Masomies & 3 & 2 & 3 & 0 & 1 \\
Carp-Paint & 4 & 3 & 3 & 0 & 1 \\
Equipment & 5 & 4 & 3 & 0 & 1 \\
Finishing & 6 & 5 & 2 & 0 & 1 \\
R.S. Delivery & 7 & 6 & 1 & 0 & 1 \\
\hline
\end{tabular}

\begin{tabular}{cc}
\multicolumn{2}{c}{ Mode \#1 } \\
\hline$d_{q 1}$ & $a_{q k 1}$ \\
\hline 7 & 8 \\
6 & 5 \\
5 & 8 \\
6 & 3 \\
5 & 5 \\
5 & 10 \\
1 & 3 \\
\hline
\end{tabular}

\begin{tabular}{cc}
\hline \multicolumn{2}{c}{ Mode \#2 } \\
\hline$d_{q 2}$ & $a_{q k 2}$ \\
\hline 4 & 14 \\
3 & 10 \\
3 & 13 \\
3 & 6 \\
3 & 8 \\
3 & 17 \\
1 & 3 \\
\hline
\end{tabular}

In Figure 4, the obtained result for an instance of the optimization problem for the example of implementation is displayed considering a resource availability of 37 monetary units per period, continuous activity execution and the makespan as objective function. In the upper side of the figure, the optimized LSM project schedule combining different execution modes and acceleration routines is presented. In the middle, a summary table presenting the values of $X_{q j t m}$ is displayed; in the lower side a Gantt diagram synthesizing daily resource consumption per activity is shown. The complete computational experimentation and quantitative results in Excel files can be downloaded from https://goo.gl/isjKMc.

To test the MRCPSP model proposed by the authors, four scenarios for the building construction scheduling are evaluated. The scenarios considered are: (1) Minimization of project makespan with activity continuity restriction (2) minimization of project makespan with allowed activity fragmentation; (3) minimization of project tardiness with continuity restriction; and (4) minimization of project tardiness with allowed activity fragmentation. Each scenario is evaluated under 15 different resource availability instances, from 31 to 45 resource units per period, yielding 60 solved instances.

Additionally, the resource efficiency consumption of the obtained schedules is measured throughout seven indicators: The sum of squares (SSQR) (Burguess \& Killebrew, 1962), Sum of Differences of Consecutive Daily Resources (SCDCR) (Florez, Castro-Lacouture, \& Medaglia, 2012), the Sum of Squares of Differences of Consecutive Daily Resources (SSDCDR) (Ponz-Tienda J. , 
Salcedo-Bernal, Pellicer, \& Benlloch-Marco, 2017), the Resource Improvement Coefficient (RIC) (Harris, Precedence and Arrow Networking Techniques for Construction, 1978), the Resource Idle Days (RID) (El-
Rayes \& Jun, 2009), and two new efficiency indexes developed by the authors: the Resource SurplusConsumption Ratio (RSCR), and the Resource Consumption-Availability Ratio (RCAR).

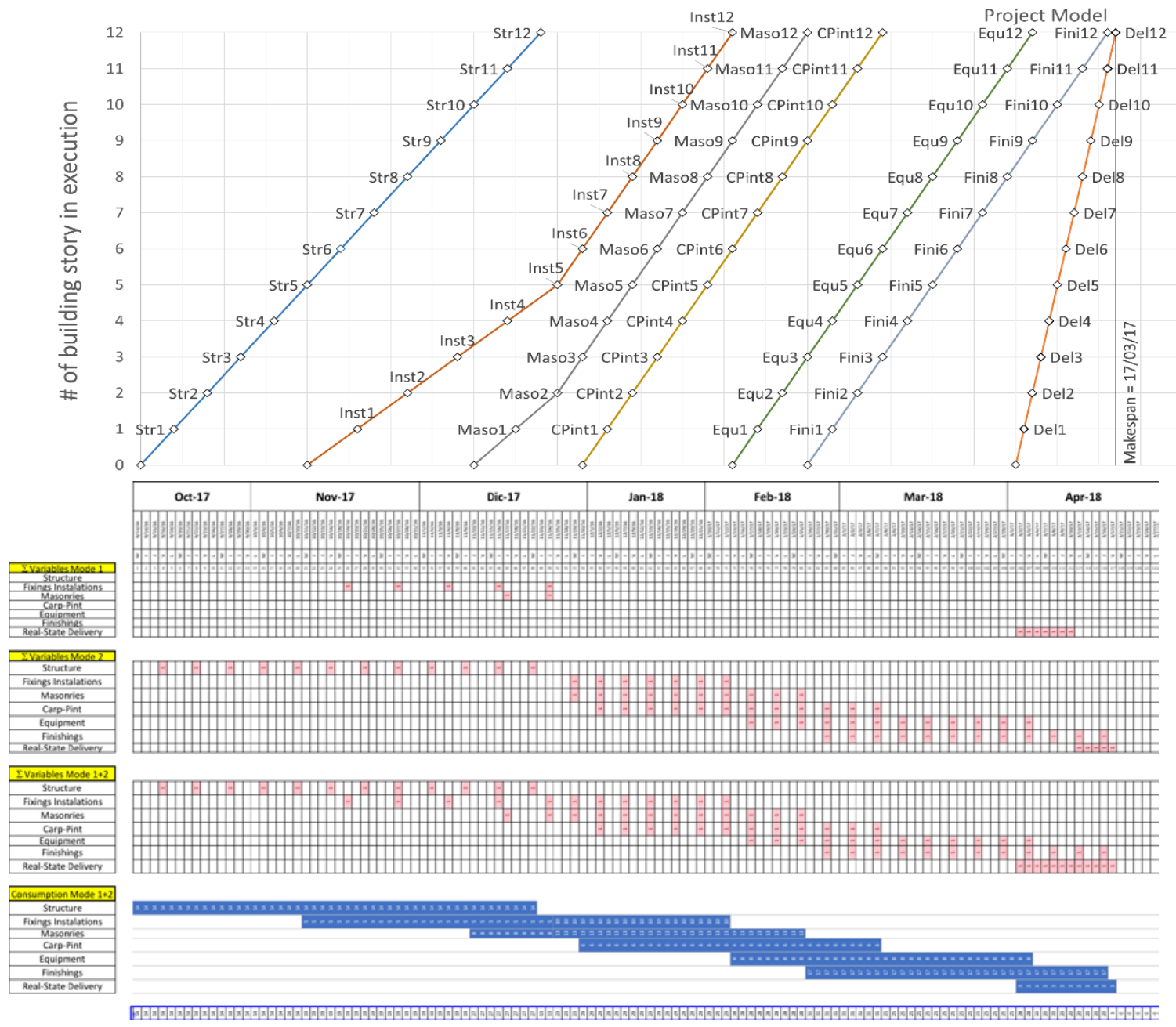

Figure 4 Example of LSM, decision variables and temporal diagram
Graphical representation and analysis of the efficiency indexes SSQR, SCDCR and SSCDCR are not developed because these indexes calculation equations are biased by the project makespan. In this order, they may provide erroneous information to practitioners when comparing two or more project schedules (Generally these indexes are only useful when the comparable schedules have the same project duration). Contrary, index RIC, RID, RSCR and RCAR truly allows authors to compare the efficiency associated with resource leveling and consumption in different projects.

The formulas to compute the previously mentioned efficiency indexes are shown in equations 10 to 16 , respectively. Note that in these equations, variable $\varepsilon_{t k}$ refers to the project consumption of the resource $k$ in a particular period of time $t$. The computation of $\varepsilon_{t k}$ based on the binary formulation used by the proposed model, is exposed in equation 17.

$$
\begin{aligned}
& S_{\text {makespan }-1} R_{k=1}=\sum_{t k}^{\text {makespan }} \\
& S C D C R_{k}=\varepsilon_{t k}+\sum_{\substack{t=1 \\
\text { makespan-1 }}}^{\text {makespan-1 }}\left|\varepsilon_{t k}-\varepsilon_{t+1, k}\right|+\varepsilon_{\text {makespan }, k} \\
& \operatorname{SSDCR}_{k}=\varepsilon_{t k}{ }^{2}+\sum_{t=1}^{\text {makespan }-1}\left(\varepsilon_{t k}-\varepsilon_{t+1, k}\right)^{2}+\varepsilon_{\text {makespan }, k^{2}} \\
& R I C_{k}=\frac{\text { Makespan } * \sum_{t=1}^{\text {makespan }} \varepsilon_{t k}{ }^{2}}{\left(\sum_{t=1}^{\text {makespan }} \varepsilon_{t k}\right)^{2}} \\
& \sum_{t=1}^{\operatorname{mak}} \min \left(\max \left(\varepsilon_{1 k}, \ldots, \varepsilon_{t k}\right) \max \left(\varepsilon_{t k}, ., \varepsilon_{\text {makespan }, k}\right)\right)-\varepsilon_{t k}
\end{aligned}
$$




$$
\begin{aligned}
& \text { RSCR }_{k}=\frac{\text { Total resource } k \text { surpluss }}{\text { Total resource } k \text { consumption }} \\
& =\frac{\sum_{t=1}^{\text {makespan }} u_{k}-\varepsilon_{t k}}{\sum_{t=1}^{\text {makespan }} \varepsilon_{t k}} \\
& R C A R_{k}=\frac{\text { Total resource } k \text { consumption }}{\text { Total resource } k \text { availability }} \\
& =\frac{\sum_{t=1}^{\text {makespan }} \varepsilon_{t k}}{\text { Makespan } * u_{k}} \\
& \varepsilon_{t k}=\sum_{m=1}^{M} \sum_{q=1}^{N}\left(a_{q k m} \cdot \sum_{t=t}^{t+d_{q}-1} \sum_{j=1}^{N} X_{q j t m}\right)
\end{aligned}
$$

The information regarding the project schedule tardiness, makespan in labor days and resource efficiency consumption is registered for each instance and scenario of the computational experimentation. The scheduling results obtained after running the mathematical model under the four scenarios are shown in Tables 2 to 5 . Table 2 shows the values for the makespan minimization as objective function with allowed activity fragmentation. The third column corresponds to the tardiness for the obtained makespan. Additionally, columns four to nine displays the efficiency indexes for each one of the instances. Table 3 is similar to the second with the difference that all the activities are executed in a continuous way. Tables 4 and 5 show the same information as Tables 2 and 3 with the

\begin{tabular}{|c|c|c|c|c|c|c|c|c|c|}
\hline $\begin{array}{l}\text { Resourc } \\
\text { e }\end{array}$ & $\begin{array}{l}\text { Makes } \\
\text { pan }\end{array}$ & $\begin{array}{l}\text { Tardine } \\
\text { ss }\end{array}$ & SSQR & $\begin{array}{l}\text { SCD } \\
\text { CR }\end{array}$ & $\begin{array}{l}\text { SSDC } \\
\text { DR }\end{array}$ & $\begin{array}{c}\mathrm{RI} \\
\mathrm{C}\end{array}$ & RID & $\begin{array}{l}\text { RSC } \\
\mathrm{R}\end{array}$ & $\begin{array}{l}\text { RCA } \\
\mathrm{R}\end{array}$ \\
\hline 31 & 110 & 5,559 & 69,125 & 114 & 1,051 & 1, & 72 & $28 \%$ & $78 \%$ \\
\hline 32 & 108 & 5,407 & 70,658 & 227 & 1,940 & 1 , & 160 & $30 \%$ & $77 \%$ \\
\hline 33 & 108 & 5,407 & 70,658 & 227 & 1,940 & 1, & 160 & $34 \%$ & $75 \%$ \\
\hline 34 & 107 & 5,319 & 71,831 & 244 & 1,772 & 1, & 215 & $37 \%$ & $73 \%$ \\
\hline 35 & 106 & 5,241 & 72,997 & 241 & 1,963 & 1 , & 197 & $39 \%$ & $72 \%$ \\
\hline 36 & 105 & 5,232 & 73,767 & 211 & 1,556 & 1 , & 183 & $42 \%$ & $70 \%$ \\
\hline 37 & 105 & 5,232 & 73,767 & 211 & 1,556 & 1, & 183 & $46 \%$ & $69 \%$ \\
\hline 38 & 103 & 5,069 & 77,041 & 272 & 3,507 & 1, & 249 & $47 \%$ & $68 \%$ \\
\hline 39 & 102 & 5,035 & 77,461 & 220 & 1,675 & 1, & 199 & $49 \%$ & $67 \%$ \\
\hline 40 & 102 & 5,035 & 77,461 & 220 & 1,675 & 1 , & 199 & $53 \%$ & $65 \%$ \\
\hline 41 & 102 & 5,018 & 78,376 & 220 & 2,314 & 1, & 218 & $57 \%$ & $64 \%$ \\
\hline 42 & 102 & 5,018 & 78,376 & 220 & 2,314 & 1 , & 218 & $61 \%$ & $62 \%$ \\
\hline 43 & 102 & 5,018 & 78,376 & 220 & 2,314 & 1 , & 218 & $65 \%$ & $61 \%$ \\
\hline 44 & 102 & 5,018 & 78,376 & 220 & 2,314 & 1 , & 218 & $68 \%$ & $59 \%$ \\
\hline 45 & 100 & 4,953 & 81.839 & 281 & 3,317 & 1 , & 348 & $69 \%$ & $59 \%$ \\
\hline
\end{tabular}
difference that tardiness is selected as the objective function.

Table 2.

\begin{tabular}{|c|c|c|c|c|c|c|c|c|c|}
\hline $\begin{array}{l}\text { Resourc } \\
\mathrm{e}\end{array}$ & $\begin{array}{l}\text { Makes } \\
\text { pan }\end{array}$ & $\begin{array}{l}\text { Tardine } \\
\text { ss }\end{array}$ & SSQR & $\begin{array}{l}\text { SCD } \\
\text { CR }\end{array}$ & $\begin{array}{l}\text { SSDC } \\
\text { DR }\end{array}$ & $\begin{array}{l}\text { RI } \\
\mathrm{C}\end{array}$ & RID & $\begin{array}{l}\mathrm{RSC} \\
\mathrm{R} \\
\end{array}$ & $\begin{array}{l}\text { RCA } \\
\mathrm{R}\end{array}$ \\
\hline 31 & 117 & 5,925 & 65,027 & 85 & 852 & 1 , & 102 & $36 \%$ & $73 \%$ \\
\hline 32 & 115 & 5,775 & 66,244 & 91 & 783 & 1 , & 205 & $38 \%$ & $72 \%$ \\
\hline 33 & 115 & 5,767 & 66,207 & 92 & 832 & 1 , & 230 & $42 \%$ & $70 \%$ \\
\hline 34 & 115 & 5,814 & 66,766 & 102 & 947 & 1 , & 223 & $47 \%$ & $68 \%$ \\
\hline 35 & 111 & 5,611 & 69,415 & 118 & 1,138 & 1 , & 176 & $46 \%$ & $69 \%$ \\
\hline 36 & 111 & 5,611 & 69,415 & 118 & 1,138 & 1 , & 176 & $50 \%$ & $67 \%$ \\
\hline 37 & 111 & 5,611 & 69,415 & 118 & 1,138 & 1 , & 176 & $56 \%$ & $65 \%$ \\
\hline 38 & 104 & 5,229 & 76,751 & 97 & 994 & 1 , & 103 & $48 \%$ & $67 \%$ \\
\hline 39 & 104 & 5,229 & 76,751 & 97 & 994 & 1 , & 103 & $52 \%$ & $66 \%$ \\
\hline 40 & 104 & 5,241 & 76,760 & 83 & 816 & 1 , & 96 & $56 \%$ & $64 \%$ \\
\hline 41 & 104 & 5,241 & 76,760 & 83 & 816 & 1 , & 96 & $60 \%$ & $62 \%$ \\
\hline 42 & 104 & 5,241 & 76,760 & 83 & 816 & 1 , & 96 & $64 \%$ & $61 \%$ \\
\hline 43 & 104 & 5,241 & 76,760 & 83 & 816 & 1 , & 96 & $68 \%$ & $60 \%$ \\
\hline 44 & 104 & 5,179 & 77,273 & 103 & 1,078 & 1 , & 73 & $72 \%$ & $58 \%$ \\
\hline 45 & 100 & 5,103 & 81,934 & 109 & 1,162 & 1 , & 161 & $69 \%$ & $59 \%$ \\
\hline
\end{tabular}

Minimization of objective function: Makespan with allowed activity fragmentation.

Table 3.

Minimization of objective function: Makespan with activities continuously executed.

Figure 5 shows that activity fragmentation, under all the makespan than the obtained when all activities are executed studied scenarios, provides schedules with shorter continuously. Also, under some resource availability 
conditions, the project makespan obtained after minimizing both objective functions under the same conditions are not equal. Makespan as objective function has shown that the optimized schedules obtained have equal or shorter makespan in comparison with the optimized schedules generated when tardiness is minimized.

Similarly, Figure 6 shows that activity fragmentation, under all the scenarios studied, also provides schedules with shorter tardiness. As well, the project tardiness obtained, after minimizing both objective functions, is not equal under continuous and discontinuous conditions. Tardiness objective function has shown that the schedules obtained have equal or shorter tardiness in comparison with the schedules generated when the makespan is minimized. Figure 5 and Figure 6 indicate that minimizing the project makespan is not equal to minimizing the tardiness as the sum of the activities starting times.

Table 4.

Minimization of objective function: Tardiness with allowed activity fragmentation.

\begin{tabular}{|c|c|c|c|c|c|c|c|c|c|}
\hline $\begin{array}{l}\text { Resourc } \\
\text { e }\end{array}$ & $\begin{array}{l}\text { Makes } \\
\text { pan }\end{array}$ & $\begin{array}{l}\text { Tardine } \\
\text { ss }\end{array}$ & SSQR & $\begin{array}{l}\text { SCD } \\
\text { CR }\end{array}$ & $\begin{array}{l}\text { SSDC } \\
\text { DR }\end{array}$ & $\begin{array}{l}\mathrm{RI} \\
\mathrm{C}\end{array}$ & RID & $\begin{array}{l}\text { RSC } \\
\mathrm{R}\end{array}$ & $\begin{array}{l}\text { RCA } \\
\text { R }\end{array}$ \\
\hline 31 & 110 & 5,458 & 69,097 & 151 & 1,012 & 1, & 93 & $28 \%$ & $78 \%$ \\
\hline 32 & 108 & 5,294 & 70,992 & 221 & 1,758 & 1, & 142 & $30 \%$ & $77 \%$ \\
\hline 33 & 108 & 5,290 & 71,006 & 229 & 1,784 & 1, & 159 & $34 \%$ & $75 \%$ \\
\hline 34 & 108 & 5,258 & 71,361 & 247 & 1,784 & 1, & 208 & $38 \%$ & $73 \%$ \\
\hline 35 & 107 & 5,204 & 72,563 & 277 & 2,256 & 1 , & 200 & $41 \%$ & $71 \%$ \\
\hline 36 & 105 & 5,185 & 73,881 & 253 & 1,896 & 1 , & 175 & $42 \%$ & $70 \%$ \\
\hline 37 & 105 & 5,185 & 73,881 & 253 & 1,896 & 1 , & 175 & $46 \%$ & $69 \%$ \\
\hline 38 & 103 & 4,987 & 76,996 & 250 & 1,942 & 1 , & 204 & $47 \%$ & $68 \%$ \\
\hline 39 & 102 & 4,981 & 77,800 & 272 & 2,187 & 1 , & 226 & $49 \%$ & $67 \%$ \\
\hline 40 & 102 & 4,979 & 77,820 & 282 & 2,235 & 1, & 232 & $53 \%$ & $65 \%$ \\
\hline 41 & 102 & 5,018 & 78,376 & 220 & 2,314 & 1, & 218 & $57 \%$ & $64 \%$ \\
\hline 42 & 102 & 4,978 & 77,864 & 288 & 2,363 & 1 , & 243 & $61 \%$ & $62 \%$ \\
\hline 43 & 102 & 4,978 & 77,864 & 288 & 2,363 & 1, & 243 & $65 \%$ & $61 \%$ \\
\hline 44 & 102 & 4,974 & 78,475 & 362 & 3,173 & 1 , & 382 & $68 \%$ & $59 \%$ \\
\hline 45 & 100 & 4,906 & 81,070 & 340 & 2,889 & 1 , & 331 & $69 \%$ & $59 \%$ \\
\hline
\end{tabular}

Table 5.

Minimization of objective function: Makespan with activities continuously executed.

\begin{tabular}{|c|c|c|c|c|c|c|c|c|c|}
\hline $\begin{array}{l}\text { Resourc } \\
\text { e }\end{array}$ & $\begin{array}{l}\text { Makes } \\
\text { pan }\end{array}$ & $\begin{array}{l}\text { Tardine } \\
\text { ss }\end{array}$ & SSQR & $\begin{array}{l}\text { SCD } \\
\text { CR } \\
\end{array}$ & $\begin{array}{l}\text { SSDC } \\
\text { DR }\end{array}$ & $\begin{array}{l}\text { RI } \\
\mathrm{C}\end{array}$ & RID & $\begin{array}{l}\mathrm{RSC} \\
\mathrm{R} \\
\end{array}$ & $\begin{array}{l}\text { RCA } \\
\mathrm{R}\end{array}$ \\
\hline 31 & 117 & 5,925 & 65,027 & 85 & 852 & 1 , & 102 & $36 \%$ & $73 \%$ \\
\hline 32 & 115 & 5,667 & 66,767 & 85 & 863 & 1, & 121 & $38 \%$ & $72 \%$ \\
\hline 33 & 115 & 5,667 & 66,767 & 85 & 863 & 1, & 121 & $42 \%$ & $70 \%$ \\
\hline 34 & 115 & 5,667 & 66,767 & 85 & 863 & 1, & 121 & $47 \%$ & $68 \%$ \\
\hline 35 & 111 & 5,605 & 69,650 & 129 & 1,351 & 1, & 192 & $46 \%$ & $69 \%$ \\
\hline 36 & 111 & 5,605 & 69,650 & 129 & 1,351 & 1, & 192 & $50 \%$ & $67 \%$ \\
\hline 37 & 111 & 5,605 & 69,650 & 129 & 1,351 & 1, & 192 & $54 \%$ & $65 \%$ \\
\hline 38 & 104 & 5,229 & 76,751 & 97 & 994 & 1, & 103 & $48 \%$ & $67 \%$ \\
\hline 39 & 104 & 5,229 & 76,751 & 97 & 994 & 1, & 103 & $52 \%$ & $66 \%$ \\
\hline 40 & 104 & 5,229 & 76,751 & 97 & 994 & 1, & 103 & $56 \%$ & $64 \%$ \\
\hline 41 & 104 & 5,226 & 76,949 & 109 & 1,144 & 1, & 115 & $60 \%$ & $62 \%$ \\
\hline 42 & 104 & 5,226 & 76,949 & 109 & 1,144 & 1, & 115 & $64 \%$ & $61 \%$ \\
\hline 43 & 104 & 5,226 & 76,949 & 109 & 1,144 & 1, & 115 & $68 \%$ & $60 \%$ \\
\hline 44 & 104 & 5,157 & 77,778 & 109 & 1,162 & 1, & 63 & $72 \%$ & $58 \%$ \\
\hline 45 & 100 & 5,067 & 82,056 & 109 & 1,162 & 1, & 156 & $69 \%$ & $59 \%$ \\
\hline
\end{tabular}



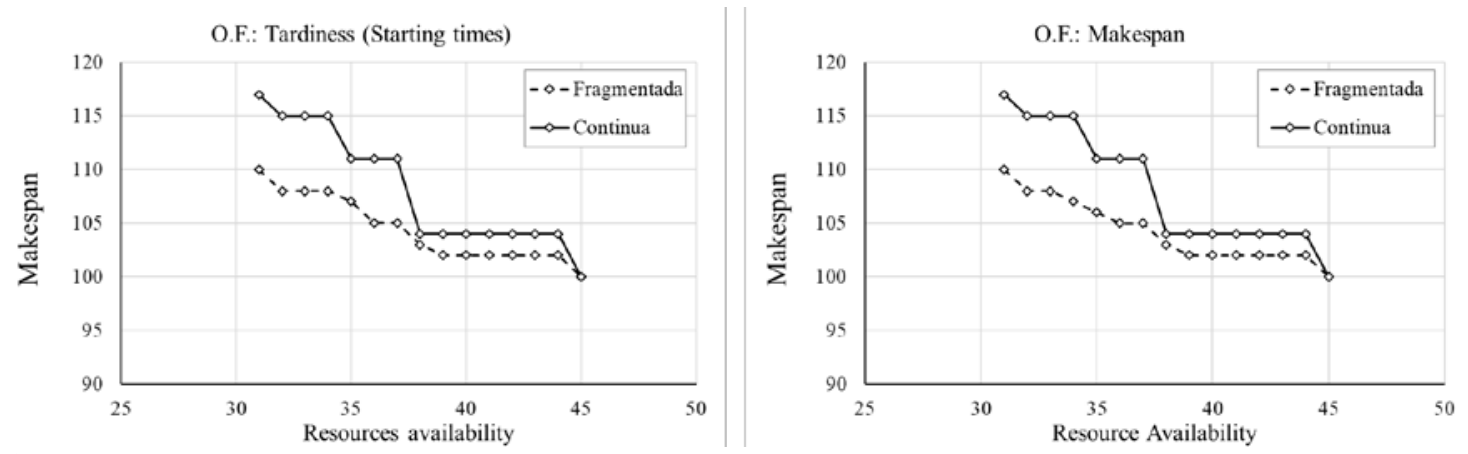

Figure 5. Project makespan vs. resource consumption under activity continuity and fragmented conditions.
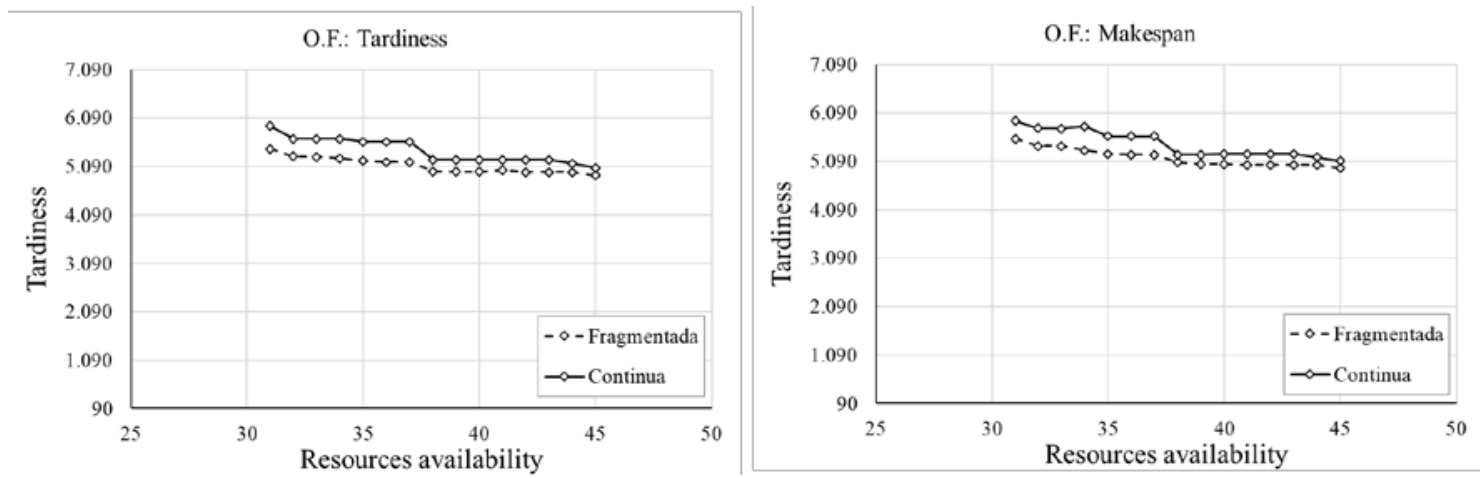

Figure 6 Project tardiness vs. resource consumption under activity continuity and fragmented conditions.

With the aim to analyze the correlation between the use of a specific objective function and the project's resource consumption efficiency, the authors have displayed valuable information in Figure 7 to 10. Figure 7 shows that, when activity fragmentation is allowed, there is no correlation that can state that the use of a specific objective function provides a better resource consumption efficiency.
Similarly, Figure 8 shows that, when activity continuity execution is guaranteed, there is also no correlation that can state that the use of a specific objective function provides better efficiency in the resource consumption. 

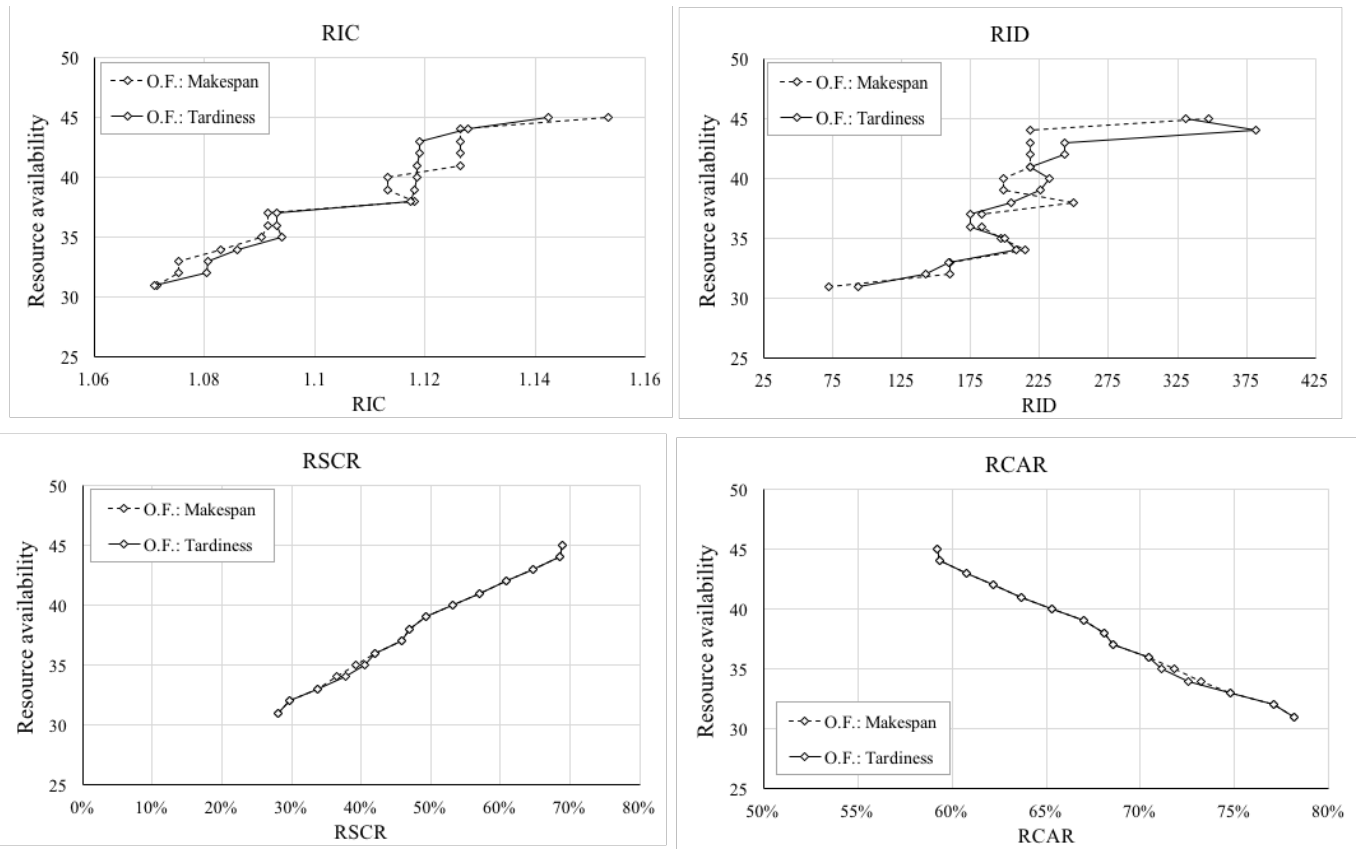

Figure 7. Resource consumption efficiency indexes under different optimization objective functions (tardiness, makespan) for continuous activities.

Additionally, Figure 9 (makespan as objective function) and Figure 10 (tardiness as objective function), indexes RSCR and RCAR, suggest that less monetary resource surplus is left behind when activities are allowed to fragmentize. Additionally, RIC index graphs propose there is no evidence that can state that fragmented activity conditions provide a better resource leveling shape in terms of uniform resource consumption. Finally, RID index suggests that fragmentation conditions result in a better resource leveling conditions in terms of idle days, when soft resource availability restrictions are imposed. As resource availability is hardened, both continuity activity conditions tend to provide a very similar RID index. In general, as it can be observed in Figure 9 and 10, the index behavior in relation with the resource availability is very similar using makespan or tardiness as objective function.

As partial conclusion, Figure 7 to 10 suggest that the decreasing of resource availability provides project schedules with a more efficient consume of resources. 

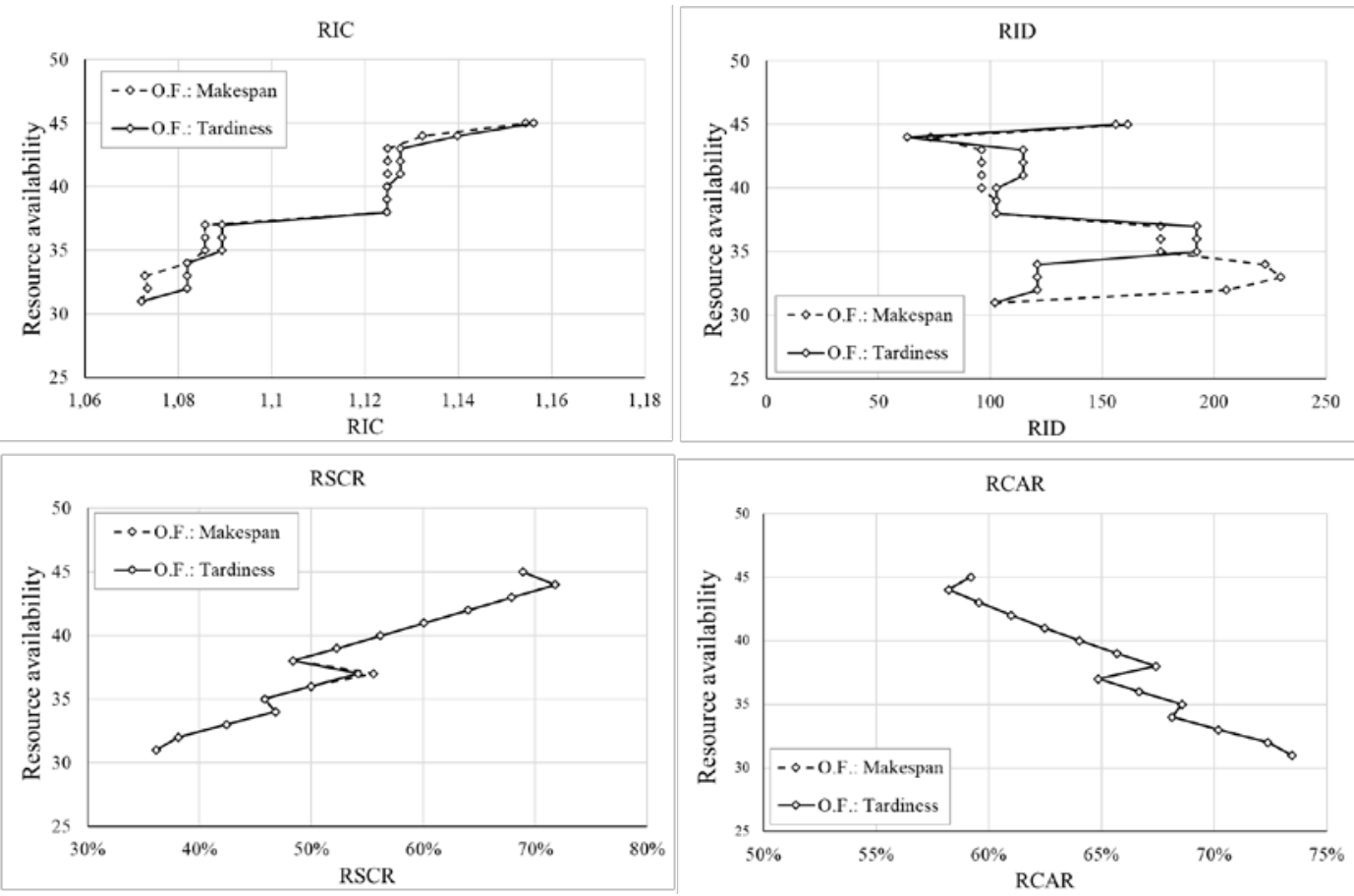

Figure 8. Resource availability vs. resource consumption efficiency indexes under different optimization objective functions (tardiness, makespan) for non-continuous activities.
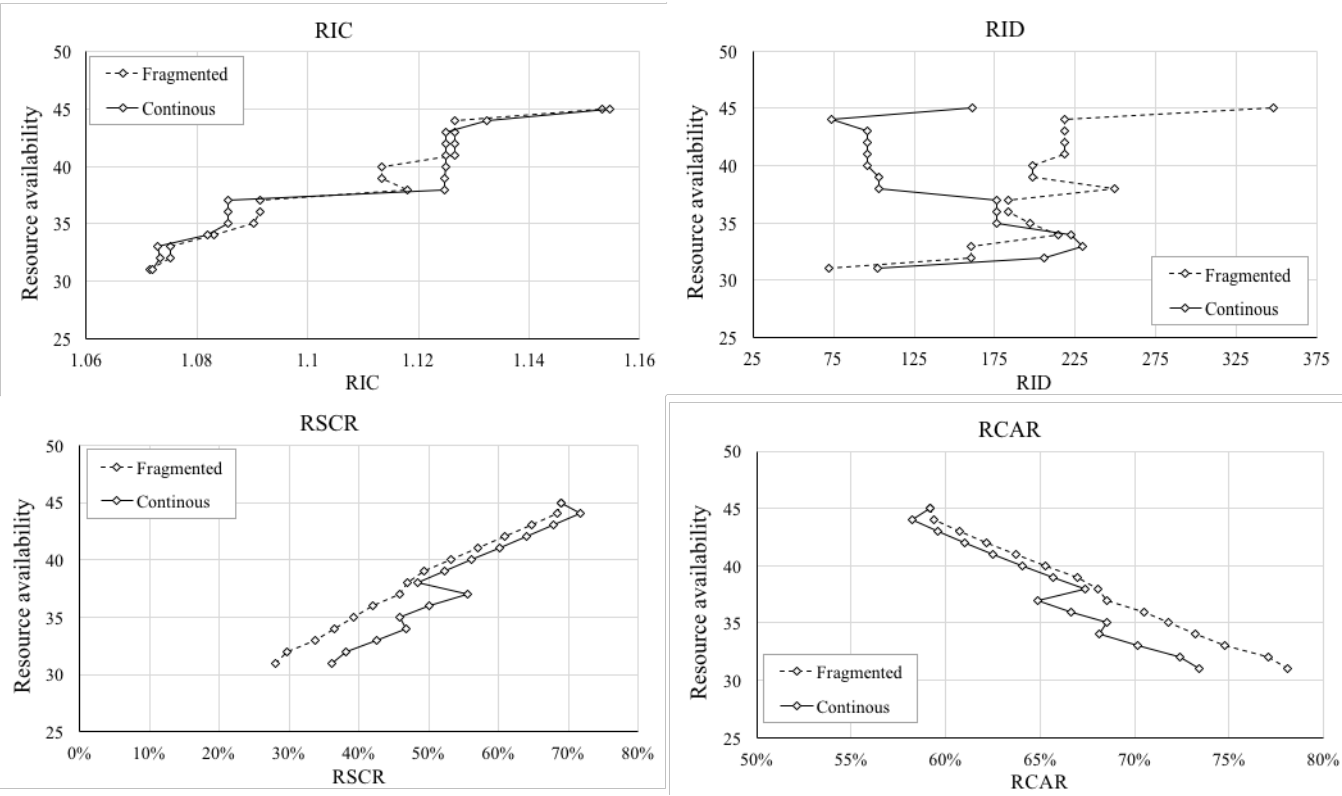

Figure 9. Resource availability vs. Resource consumption efficiency indexes under two activity execution conditions (Fragmented, Continuous) for makespan objective function. 

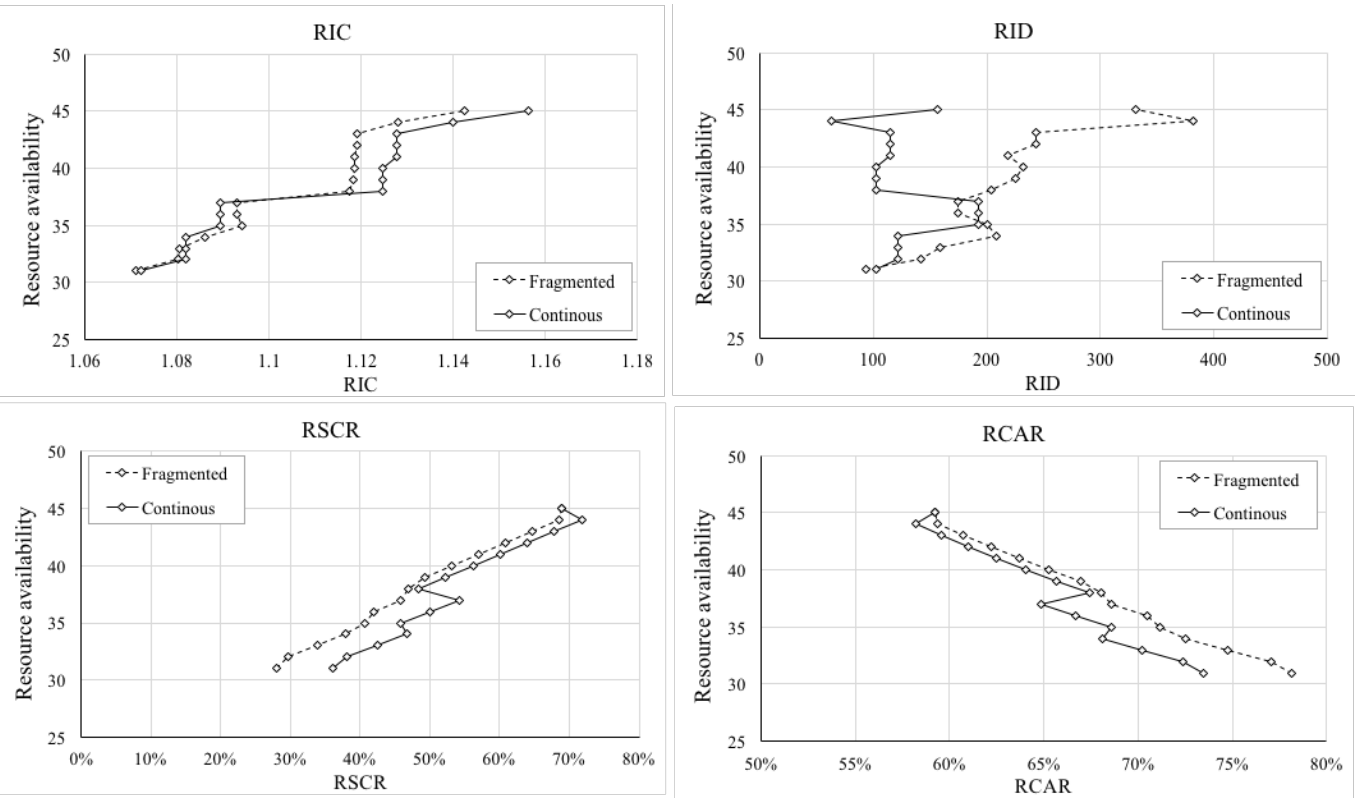

Figure 10. Resource availability vs. resource consumption efficiency indexes under two activity execution conditions (fragmented, continuous) for tardiness objective function.

Regarding the acceleration routine implementation, the authors also registered the number of activities that applied an acceleration routine during the activity execution in each scenario. Table 6 shows that in all scenarios, the scheduling optimization have applied acceleration routines to activities execution in order minimize the project makespan or tardiness.
Despite of the correlation coefficients between resource availability and the number of activities with acceleration routines have achieved values up to -0.49 , there is not a clear linear correlation between these variables. It seems that the number of accelerated activities vary depending the particular needs of a specific project, the schedule conditions and the optimization needs.

Table 6.

Number of activities that applied acceleration routines in each scenario test.

\begin{tabular}{|c|c|c|c|c|}
\hline \multirow{2}{*}{ Resource availability } & \multicolumn{2}{|c|}{ Makespan } & \multicolumn{2}{|c|}{ Tardiness } \\
\hline & Fragmented & Continuous & Fragmented & Continuous \\
\hline 31 & 2 & 3 & 2 & 3 \\
\hline 32 & 2 & 4 & 2 & 3 \\
\hline 33 & 2 & 4 & 2 & 3 \\
\hline 34 & 3 & 4 & 3 & 3 \\
\hline 35 & 4 & 5 & 4 & 5 \\
\hline 36 & 4 & 5 & 4 & 5 \\
\hline 37 & 4 & 5 & 4 & 5 \\
\hline 38 & 2 & 3 & 2 & 3 \\
\hline 39 & 3 & 3 & 2 & 3 \\
\hline 40 & 3 & 3 & 2 & 3 \\
\hline 41 & 4 & 3 & 4 & 4 \\
\hline 42 & 4 & 3 & 2 & 4 \\
\hline 43 & 4 & 3 & 2 & 4 \\
\hline 44 & 4 & 4 & 2 & 3 \\
\hline 45 & 1 & 2 & 1 & 2 \\
\hline Correlation Coefficient & 0.25 & -0.49 & -0.27 & -0.12 \\
\hline
\end{tabular}




\section{CONCLUSIONS, LIMITATIONS AND RECOMMENDATIONS FOR FUTURE RESEARCH}

Creating efficient construction projects schedules is one of the main priorities that every construction has during its planning stage. In many occasions, practitioners have to build efficient schedules in order to battle inefficient resource consumption fluctuations or restrictive resource availability.

In the case of construction projects that involve repetitive activities, practitioners and researchers have noticed that traditional RCPSP models failed to allocate in an efficient manner the resource consumption considering activity overlapping, fragmentation, multiple activity execution modes, and sub-activities precedence relationships. To fulfill this gap, several authors have developed heuristic and metaheuristic models especially shaped to overcome the challenges that emerged with repetitive activities scheduling. However, the literature review has exposed that the incorporation of activity acceleration routines, a common and real problem that engineers face with, seems to be missed.

Currently, advanced MRCPSP models for repetitive activities in construction have achieved makespan minimization considering the optimum execution of crews and starting times for all sub-activities. Nonetheless, wild fluctuations on crew sizes within a same activity may result in inefficient, problematic or unrealistic construction schedules.

For this reason, the authors consider that the best way to simultaneously implement multiple execution modes in a same activity, is throughout the use of unidirectional changes of optimum crew size throughout an activity execution, which are denoted as acceleration routines. Therefore, with the aim to build a more realistic MRCPSP model for repetitive activity scheduling, this article presents a holistic approach to the MRSCP-RA. This model allows practitioners to obtain optimal schedules based in project duration objective functions, which simultaneously provides a realistic approach of the MRCPSP through the implementation of acceleration routines.

The proposal computes the times and execution modes for all sub-activities involved in the project, based on continuity restrictions, precedence relationships, optimum crew size and activities acceleration routines. This article contributes to the body of knowledge of construction project scheduling in several ways:

- It provides a more realistic MRCPSP model for Repetitive Activities that better fits to real construction projects.

- MRCPSP for repetitive activities solve to optimality.

- Controlled activity acceleration routines are incorporated to the MRCPSP-RA model.
- It introduces an easy criterion to implement scheduling problems in spreadsheets to generate global optimum schedule solutions, proposing a compact representation based on matrix that requires less information for the input variables than traditional models.

- It shows a complete computational experimentation over a real construction project, considering several scenarios of resource availabilities and continuity conditions.

- It analyzes the resources efficiency indexes comparing them to resource consumptions, continuity of activities and objective functions that reveal that fragmented activities do not provide better resource efficiency profiles.

The model can benefit current industrial construction processes such as bridge and high-rise building construction among others. The case of study is a real example of how, the mathematical model proposed, can be used to schedule activities in high-rise housing complexes in low socioeconomic districts. The scope of this type of projects and the industrial process used to build the infrastructure, largely promote the occurrence of repetitive activities that can be scheduled with the proposed mathematical model.

Finally, the authors identify eight model limitations that open space to future research. First, the mathematical model proposed does not consider soft logic scheduling optimization. Second, even though the model can be adjusted to contemplate non-repetitive activities, it does not consider them. Third, only identical sub-activity units are considered from a practical point of view, but this issue can be included easily. Fourth, negative acceleration routines (deceleration) are not allowed by the mathematical model restrictions. Fifth, sub-activity segments are assumed to be linear and non-interruptible. Sixth, only minimal SS, FS, FS, FF relations are allowed. Seventh, calendar effect on the scheduling process is not allowed. Last, a larger number of activities and execution modes can result in a high computational effort that may limit the model application. This limitation can be partially solved applying parallel computing to improve the computational cost. In addition, metaheuristic models based in the proposed model can be developed in order to overcome computational limitation.

\section{ACKNOWLEDGMENTS}

This research was partially supported by the FAPA program of Universidad de Los Andes, Colombia (code P14.246922.005/01). The authors would also like to thank the research group of Construction Engineering and Management (INgeco) at Universidad de los Andes. 


\section{REFERENCES}

Adeli, H., \& Karim, A. (1997). Scheduling/Cost Optimization and Neural Dynamics Model for Construction. Journal of construction engineering and management, 123, 450-458.

Anagnostopoulos, K. P., \& Koulinas, G. K. (2010). A simulated annealing hyperheuristic for construction resource levelling. Construction Management and Economics, 28(2), 163-175. doi:10.1080/01446190903369907.

Arditi, D., Tokdemir, O., \& Suh, K. (2002). Challenges in Line-of-Balance Scheduling. (ASCE, Ed.) Journal of construction engineering and management, 545-556.

Benjaoran, V., Tabyang, W., \& Sooksil, N. (2015). Precedence relationship options for the resource levelling problem using a genetic algorithm. Construction Management and Economics, 33(9), 711-723. doi:10.1080/01446193.2015.1100317.

Biruk, S., \& Jaskowski, P. (2017). Scheduling linear construction projects with constraints on resource availability. Archives of Civil Engineering, 63(1).

Burguess, A., \& Killebrew, J. (1962). Variation in activity level on a cyclic arrow diagram. Journal of Industrial Engineering, 13(2), 76-83.

Chakraborty, P., Roy, G. G., Das, S., Jain, D., \& Abraham, A. (2009). An Improved Harmony Search Algorithm with Differential Mutation Operator. Fundamenta Informaticae, 95(4), 401-426. doi:10.3233/FI2009-157

Demeulemeester, E., \& Herroelen, W. (2002). Project Scheduling: A Research Handbook. Kluwer Academic Publishers.

El-Rayes, K., \& Jun, D. (2009). Optimizing resource leveling in construction projects. Journal of construction engineering and management, 135(11), 1172-1180. doi:dx.doi.org/10.1061 / (ASCE) CO.1943-7862.0000097.

El-Rayes, K., \& Moselhi, O. (2001, January/Febraury). Optimazing resource utilization for repetitive construction projects. (ASCE, Ed.) Journal of construction engineering and management, 18-27.

Florez, L., Castro-Lacouture, D., \& Medaglia, A. L. (2012). Sustainable workforce scheduling in construction program management. Journal of the Operational Research Society, 64(8), 1169-1181. doi:10.1057/jors.2012.164.

Harris, R. (1978). Precedence and Arrow Networking Techniques for Construction. Wiley, Newyork.

Harris, R. (1990). Packing Method for Resource Leveling. (J. o. management, Ed.).

Hegazy, T. (2006). Computerized System for Efficient Delivery of Infrastructure Maintenance/Repair Programs. Journal of Construction Engineering and Management, 132(1).
Hegazy, T., \& Kamarah, E. (2008). Efficient Repetitive Scheduling for High-Rise Construction. Journal of construction engineering and management, 134(4), 253 264.

Herroelen, W., \& Leus, R. (2005). Project Scheduling under Uncertainty: Survey and Research Potentials. European Journal of Operational Research, 165, 289-306.

Herroelen, W., De Reyck, B., \& Demeulemeester, E. (1998). Resource-constrained project scheduling: A survey of recent developments. Computers \& Operations Research, 25, 279-302.

Hinze, J. (2002). Construction Planning and Scheduling (4th edition ed.). Upper Saddle River, NJ: Prentice Hall.

Hsie, M., Chang, C.-J., Yang, I.-T., \& Huang, C.-Y. (2009). Resource-constrained scheduling for continuous repetitive projects with. Automation in construction, 18, 942-949.

Icmeli, O. E. (1993). Project scheduling problems: A survey. International Journal of Operations \& Production Management, 13, 80-91.

Kim, J., Kim, k., \& Jee, N. (2005). Enhanced Resource Leveling Technique for Project Scheduling. Journal of Asian Architecture and Building Engineering, 4(2), 461466.

Kolish, R., \& Padman, R. (2001). An integrated survey of deterministic project scheduling. Omega The International Journal of Management Science, 29(3), 249272.

Koulinas, G., \& Anagnostopoulos, K. (2013). A new tabusearch-based hyper-heuristic algorithm for solving construction leveling problems with limited resource availabilities. Automation in Construction, 31, 169-175.

Leu, S., \& Hwang, S. (2001). Optimal Repetitive Scheduling Model with Shareable Resource Constraint. Journal of construction engineering and management, 127(4), 270-280.

Liu, S.-S., \& Wang, C.-C. (2012). Optimizing linear project scheduling with multi-skilled crews. Automation in construction, 24, 16-23.

Lumsdem, P. (1968). The line-of-balance method. Pergamon Press Limited.

Neumann, K., \& Zimmermann, J. (1999). Resource levelling for projects with schedule-dependent time windows. European Journal of Operational Research, 117, 591-605.

Neumann, K., Schwindt, C., \& Zimmermann, J. (2003). Project Scheduling with Time Windows and Scarce Resources. Berling: Springer.

Nezval, J. (1958). Foundations of flow production in construction. VEB Verlag für Bauwesen.

O’Brien, J. (1969). Scheduling handbook. New York, N.Y.: McGraw-Hill Inc.

Özdamar, L., \& Ulusoy, G. (1995). A survey on the resource-constrained project scheduling problem. IIE Transactions, 27, 574-586. 
Ponz-Tienda, J. L., Pellicer, E., Benlloch-Marco, J., \& Andrés-Romano, C. (2015). The Fuzzy Project Scheduling Problem with Minimal Generalized Precedence Relations. Computer-Aided Civil and Infrastructure Engineering, 30(11), 872-891. doi:10.1111/mice.12166.

Ponz-Tienda, J. L., Salcedo-Bernal, A., \& Pellicer, E. (2016). A Parallel Branch and Bound algorithm for the Resource Levelling Problem with minimal lags. ComputerAided Civil and Infrastructure Engineering. 32(6), 474-498 doi:10.1111/mice.12233.

Ponz-Tienda, J. L., Yepes, V., Pellicer, E., \& MorenoFlores, J. (2013). The Resource Leveling Problem with Multiple Resources. Automation in Construction, 29, 161172. doi:10.1016/j.autcon.2012.10.003.

Ponz-Tienda, J., Salcedo-Bernal, A., Pellicer, E., \& Benlloch-Marco, J. (2017). Improved Adaptive Harmony Search algorithm for the Resource Leveling Problem with minimal lags. Automation in Construction, 77, 82-92. doi:10.1016/j.autcon.2017.01.018.

Pritsker, A. A., Waiters, L. J., \& Wolfe, P. M. (1969). Multiproject scheduling with limited resources: A zero-one programming approach. Management science, 16(1), 93108. doi:http://dx.doi.org/10.1287/mnsc.16.1.93.

Rieck, J., \& Zimmermann, J. (2015). Exact Methods for Resource Leveling Problems. In Handbook on Project Management and Scheduling Vol. 1 (pp. 361-387). Springer International Publishing.

Russel, A., \& Caselton, W. (1988). Extensions to linear sched- uling optimization. (ASCE, Ed.) Journal of construction engineering and management, 114(1), 36-52.

Selinger, S. (1980). Construction planning for linear projects. (ASCE, Ed.) Journal of Constr. Div., 106(2), 195205.

Senouci, A., \& Adeli, H. (2001). Resource scheduling using neural dynamics model. Journal of construction engeneering and management, 127, 28-34.

Su, Y., \& Lucko, G. (2015). Comparison and renaissance of classic line-of-balance and linear schedule concepts for construction industry. Procedia Engineering, 123, 546-556.

Su, Y., \& Lucko, G. (2016). Linear scheduling with multiple crews based on line-of-balance and productivity scheduling method with singularity functions. Automation in construction, 70, 38-50.

Tang, Y., Liu, R., \& Wang, F. (2017). Scheduling Optimization of Linear Schedule with Constraint Programming. Computer-Aided Civil and Infrastructure Engineering, 00, 1-28.

Zhang, L.-H., \& Zou, X. (2015). Repetitive Project Scheduling: Theory and Methods. ELSEVIER. 